\title{
Ajay Kumar Mishra (Ed): Smart Ceramics: Preparation, Properties, and Applications
}

\section{Peter Myers ${ }^{1}$}

๑) Springer-Verlag GmbH Germany, part of Springer Nature 2019 had been rushed for publication, hence the lack of editorial censorship.

But let me go into some detail as to why I have made these statements. The book consists of fourteen chapters, according to the index. In the very first chapter, written by the editor, a definition of "Smart Ceramics" is provided. "They are fabricated from ultra-fine particles and the sol-gel route is the main process used for the conversion of the ultrafine particles into ceramics." But nowhere in this chapter does the term "smart ceramics" appear and is replaced by the term "nano-ceramics". The chapter describes the sol-gel process and how this process has led to nano-ceramics for applications in many areas. It was not until I read the conclusion that I found something I could agree with in that "sol-gel chemistry offers a flexible approach for obtaining a diverse range of materials".

In Chapter 2 the sol-gel process is described again but the diagram used is virtually the same as the diagram used in the first chapter; the editor should have edited or changed this. It was not until Chapter 5 that I started to read something of interest and something that could have a connection to a smart ceramic. But the problem with this chapter was that it requires a correction of the grammar and style of writing to bring it in line with other chapters. In Chapter 7 I thought things had changed when I read a header of "Non-Sol-Gel", I was wrong since the very next header was sol-gel. Chapters 8-10 are interesting dealing with membranes and fibres. But then Chapter 11 was brought back to-yes, sol-gel!

One good point of this book is the references. They are to a common format, but the format used doesn't include the year, but you cannot expect everything.

Publisher's Note Springer Nature remains neutral with regard to jurisdictional claims in published maps and institutional affiliations.

Peter Myers

peter.myers@liverpool.ac.uk

1 Department of Chemistry, University of Liverpool,

Liverpool, UK 